\title{
Evaluation of Depression and Anxiety and Its Association with CD4 Count among HIV Patients Taking Antiretroviral Therapy
}

\author{
Rajeev Lochan Khare ${ }^{1}$, Vishal Rajpoot², Surbhi Dubey ${ }^{3}$ \\ ${ }^{1}$ Department of Medicine, Pt. JNM Medical College and Dr. BRAM Hospital, Raipur, Chhattisgarh, India. \\ ${ }^{2}$ Department of Medicine, Pt. JNM Medical College and Dr. BRAM Hospital, Raipur, Chhattisgarh, India. \\ ${ }^{3}$ Department of Psychiatry, Dr. Bhimrao Ambedkar Memorial Hospital, Raipur, Chhattisgarh, India.
}

\section{ABSTRACT}

\section{BACKGROUND}

Depression and anxiety are the most common mental disorder affecting individuals with human immunodeficiency virus (HIV) infection. Anxiety is highly prevalent in HIV infected individuals in clinical studies. Early identification and treatment of depression and anxiety in patients may improve better outcome of ART Therapy. We wanted to evaluate the prevalence of depression and anxiety among HIV patients taking antiretroviral therapy and examine the predicting effect of depression and anxiety with demographics on CD4 count.

\section{METHODS}

This study was conducted in the ART Plus center in Department of Medicine, PT JNM Medical college, Raipur, Chhattisgarh and Dr. Bhim Rao Ambedkar Memorial Hospital between July 2018 and June 2019. A total of 300 patients who were enrolled in the ART plus center, gave consent to participate in study. Participants were selected in systematic random sampling method irrespective of their age, gender, ethnicity, socio-economic status, occupation, education, and present CD4 count. Starting CD4 count was assessed on enrolment to ART center and present CD4 count repeated at the time of recruitment to our study. Depression was evaluated using Hamilton Depression Rating Scale and anxiety was measured by Hamilton Anxiety Rating Scale by a Psychiatrist.

\section{RESULTS}

The first model showed $8.8 \%$ of total variance $(R=.297, R 2=.088 ; F(5,298)=5.683$; $\mathrm{p}<0.01$ ) for starting CD4 count and second model showed $6.7 \%$ of total variance $(\mathrm{R}=.259, \mathrm{R} 2=.067 ; \mathrm{F}(5,298)=4.221 ; \mathrm{p}<0.01)$ for present CD4 count with five predictor variables (depression, treatment year, gender, age, anxiety). Depression of the patients was negatively associated with starting CD4 count $(-.085, \mathrm{p}<0.01)$ before starting ART Regimen. Treatment year of the patients was positively associated with present CD4 count $(-.085, \mathrm{p}<0.01)$.

\section{CONCLUSIONS}

The study demonstrates high prevalence of anxiety and depression among HIV positive patients taking antiretroviral therapy (ART) and strong correlation of depression and anxiety and its associated factors among HIV positive patients taking ART. High depression reported lower level of CD4 count before starting ART regimen.
Corresponding Author:

Surbhi Debey,

Assistant Professor

Department of Psychiatry,

Dr. Bhimrao Ambedkar Memorial Hospital,

Raipur, Chhattisgarh, India.

E-mail:drsm16@yahoo.co.in

DOI: $10.14260 /$ jemds/2020/483

How to Cite This Article:

Khare RL, Rajpoot V, Dubey S. Evaluation of depression and anxiety and its association with CD4 count among HIV patients taking antiretroviral therapy. J. Evolution Med. Dent. Sci. 2020;9(31):2223-2227, DOI: $10.14260 /$ jemds $/ 2020 / 483$

Submission 20-04-2020,

Peer Review 25-06-2020,

Acceptance 03-07-2020,

Published 03-08-2020.

Copyright (C) 2020 JEMDS. This is an open access article distributed under Creative Commons Attribution License [Attribution 4.0 International (CC BY 4.0)]

\section{KEY WORDS}

Depression, Anxiety, HIV, CD4 Count 


\section{BACKGROUND}

Human Immunodeficiency Virus (HIV), a retrovirus, the infectious agent that causes AIDS was discovered in 1983 by Luc Montagnier, Francoise Barre- Sinoussi (Pasteur institute, Paris, France) and Robert Gallo (National Institute Of Health, Bethesda, Maryland USA), for which they were awarded noble prize in medicine in 2008. Whereas in INDIA first case was documented in 1986 among female sex worker in Chennai.(1) The Human Immunodeficiency Virus (HIV) targets the immune system and weakens people's defence systems against infections and some types of cancer. As the virus destroys and impairs the function of immune cells, infected individuals gradually become immune deficient. Immune function is usually measured by CD4 cell count.(2)

According to NACO, India has become the $3^{\text {rd }}$ biggest epidemic of HIV in global population. In year of 2017, HIV prevalence among adults of around 15-49 age group was an estimation of $0.2 \%$. As compared to different other middleincome countries, this figure is very small but because of India's larger population total of around 1.3 billion people, this equalizes to 2.1 million individual living with HIV infection.(3) PLHIV individual who are aware of their HIV positive status is 79 percent in 2017, out of which 56 percent are on antiretroviral therapy (ART). The issues that originally brought mental health workers to HIV care places to cope up with the losses and sadness by individual deaths brings to the need for mental health professionals to further manage and treat the psychiatric disorders that have association with the continued prolong risk behaviours in psychiatric populations. Depression, mania related disorder, substance abuse, cognitive impairment of some clients, and personality problem are associated with increased risk of infection by HIV. Not only mental health issues increase the risk of HIV infection, but also having of HIV/AIDS increases the lifetime prevalence of psychiatric related illness. ${ }^{(4)}$

Complexities of neuropsychiatric presentations are clearly linked together in coherent ways in the rubric of biological, immunological and socio-cultural factors. Depression is the single biggest accumulator of worldwide disability i.e. $7.5 \%$ of all years of disable individual in 2015. . International research shows significant mental disorders in people with HIV.(5) ART lowers the risk of onward transmission, ART initiation should be offered to all persons following their diagnosis of HIV. With the advent of Highly Active Anti-Retroviral Therapy (HAART), the result of HIV diseases in the developed world has changed, mortality has been declined. ART initiation should be offered to all persons following their diagnosis of HIV.(6)

Depression is among the most common mental disorder affecting individuals with human immunodeficiency virus (HIV) infection. Depressive disorder in patients with HIV/AIDS is associated with poor adherence to antiretroviral (ART) medications. Early identification and treatment of depression in such patients may improve ART medication risk factor for infection including substance abuse. Anxiety is highly prevalent in HIV infected individuals and is almost three times more frequent in people living with HIV/AIDS as compared to the general population. The prevalence of anxiety is as high as $38 \%$ in clinical studies. Early detection and treatment of anxiety related disorders results in better outcome of ART Therapy.

\section{METHODS}

Hospital based observational cross-sectional study design was adapted. 300 patients were selected through systematic random sampling from July 2018 to June 2019. Patients who were known case of HIV or recently diagnosed presented in the department of Medicine, and all ART client who attended ART clinic in Dr Bhim Rao Ambedkar Memorial Hospital Raipur, were taken for the study considering inclusion and exclusion criteria.

\section{Inclusion Criteria}

All HIV positive patients attending ART plus center with age 18 years and above will be included in the study. The study included

- $\quad$ Patient taking ART < 1 year-100.

- $\quad$ Patient taking ART 1 - 5 year-100.

- $\quad$ Patient taking ART $>5$ year-100.

\section{Exclusion Criteria}

1. Patients not willing to participate

2. Haemodynamically unstable patients.

3. Those who are unable to respond and severely ill who have hearing impairment.

4. Those undergoing treatment for psychiatric disorders before diagnosis of HIV.

5. Female patients in post-partum period.

\begin{abstract}
Instruments
Demographic Checklist- A structured questionnaire was used to collect data on socio-demographic characteristics, age, sex, education, occupation, marital status, income and substance use. Depression was assessed using Hamilton Depression Rating Scale, Anxiety was assessed using Hamilton Anxiety Rating Scale, CD4 count was assessed on enrolment to ART center and repeated when patients were recruited for study.
\end{abstract}

\section{Procedures}

The sample consisted of HIV positive patients on antiretroviral treatment coming for their routine appointment at ART Plus centre, in Dept. of medicine, Dr. Bhim Rao Ambedkar Memorial Hospital Raipur. We used systematic random sampling method for this study. Patients who had a routine appointment in the duration of this study at the ART clinic and who voluntarily were interested to participate in a study were inducted. Patients were also informed that whether they participate or not in this study, the treatment they are receiving would not be affected. Participants were also made aware that this is one-time interview, and there will be no follow up for this study.

\section{Ethical Considerations}

The study was approved by the Institutional Ethics Committee, Pt. J.N.M. Medical College Raipur, with ref. no.No./MC/Ethics/2019/93, dated 16.04.2019. 


\section{Statistical Analysis}

Data obtained was statistically analyzed with the help of (SPSS) 16th version. Cross Tab Analysis with chi-square was used to examine the association of demographic with depression and anxiety. A multiple regression models were used to examine the effect of depression and anxiety with demographic on CD4 count. Variance inflation factors (VIFs) were examined to detect multi-co linearity.

\section{RESULTS}

Majority of the study participants who were on ART are having anxiety and depression are females $37.14 \%$ as compared to males $27.7 \%$. Majority of study participants having anxiety and depression are illiterate $39.43 \%$ followed by literate (primary plus secondary schooling $28.35 \%$, graduate $20.68 \%$, post graduate $16.6 \%$.

\begin{tabular}{|ccccccc|}
\hline & Model & Sum of Squares & df & Mean Square & F & Sig. \\
\hline & Regression & 1557470.140 & 5 & 311494.028 & 5.683 & $0.000^{\mathrm{a}}$ \\
1 & Residual & $1.606 \mathrm{E} 7$ & 293 & 54810.547 & & \\
& Total & $\mathbf{1 . 7 6 2 E 7}$ & $\mathbf{2 9 8}$ & & \\
a. Predictors: (Constant), Depression, Treatment & & \\
b. Dear, Gender, Age, Anxiety & \\
\hline \multicolumn{5}{|c}{ Table 1. ANOVA Results of the First-Model with } \\
Multiple Regression Analysis for Starting CD4 Count
\end{tabular}

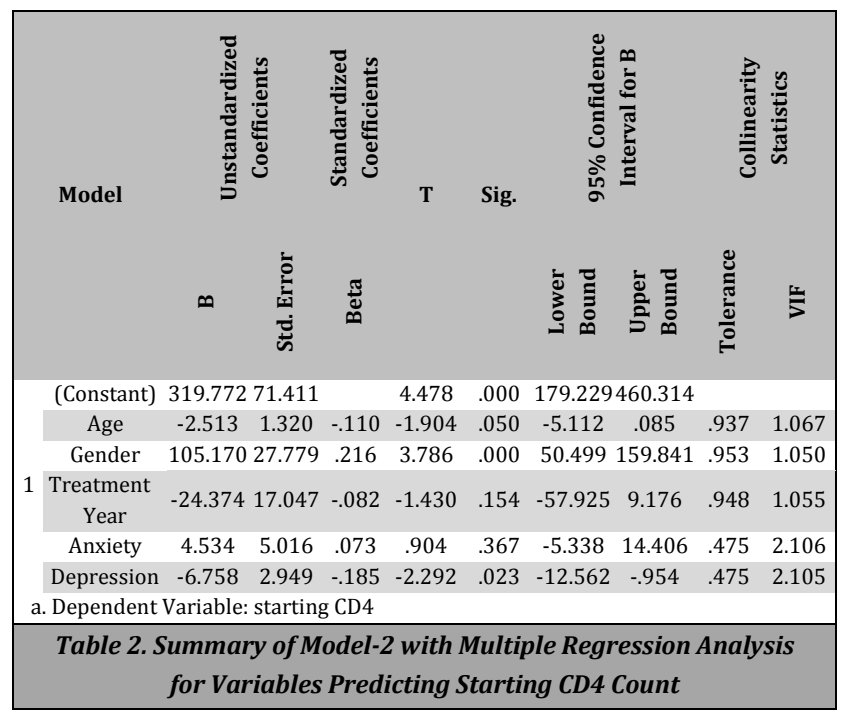

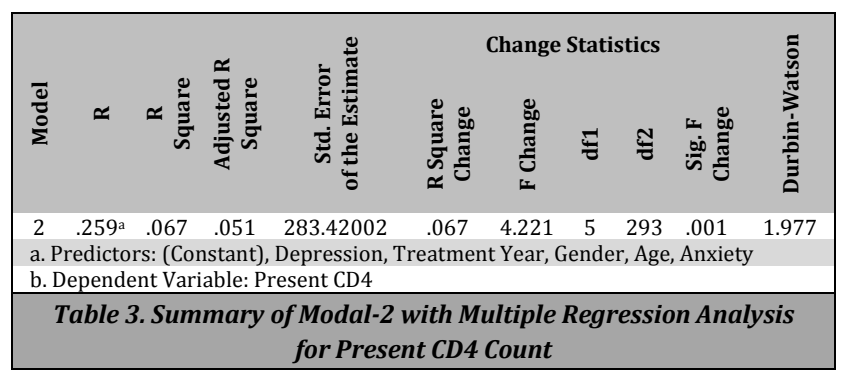

\begin{tabular}{|c|c|c|c|c|c|c|}
\hline & Model & $\begin{array}{c}\text { Sum of } \\
\text { Squares }\end{array}$ & df & Mean Square & $\mathbf{F}$ & Sig. \\
\hline \multirow{3}{*}{2} & Regression & 1695232.809 & 5 & 339046.562 & 4.221 & $.001^{\mathrm{a}}$ \\
\hline & Residual & 2.354E7 & 293 & 80326.908 & & \\
\hline & Total & $2.523 \mathrm{E} 7$ & 298 & & & \\
\hline \multicolumn{7}{|c|}{$\begin{array}{l}\text { a. Predictors: (Constant), Depression, Treatment Year, Gender, Age, Anxiety } \\
\text { b. Dependent Variable: Present CD4 }\end{array}$} \\
\hline \multicolumn{7}{|c|}{$\begin{array}{l}\text { Table 4. ANOVA Results of the Second-Model- } \\
\text { ultiple Regression Analysis for Present CD4 Count }\end{array}$} \\
\hline
\end{tabular}

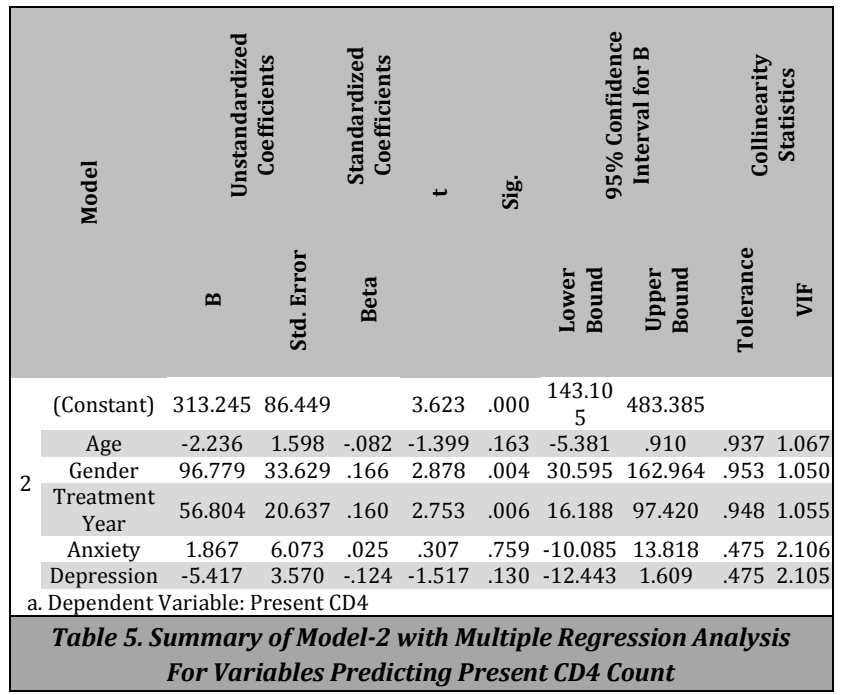

Table no. 1 and 4 indicates it clearly that VIF (variance inflation factor) values ranged from 1.050 to 2.106 , which were distant from the 4.0 criteria that may indicate multicollinearity concern (Jang, Chiriboga, Kim, \& Rhew, 2010). The first model explained $8.8 \%$ of total variance $(\mathrm{R}=.297, \mathrm{R} 2=.088 ; \mathrm{F}(5,298)=5.683 ; \mathrm{p}<0.01)$ with five predictor variables (depression, treatment year, gender, age, anxiety) for starting CD4 count. The second model explained $6.7 \%$ of total variance $(\mathrm{R}=.259, \mathrm{R} 2=.067 ; \mathrm{F}(5,298)=4.221$; $\mathrm{p}<0.01$ ) with five predictor variables (depression, treatment year, gender, age, anxiety) for present CD4 count.

Regression weighs for Depression, Treatment Year, Gender, Age and Anxiety of patients obtained from the multiple regression models depicted in Table-2 and 5. Age of the participants was negatively associated with CD4 count in starting $(-.247, \mathrm{p}<0.01)$; with increasing age patients reported low CD4 count in starting. Depression of the patients was negatively associated with CD4 count $(-.085, \mathrm{p}<0.01)$ that means high depressive patients reported lower level of CD4 count in starting. Treatment year of the patients was positively associated with CD4 count at present $(-.085, \mathrm{p}<0.01)$ that means Duration of ART Regimen reported high level of CD4 count at present.

\section{DISCUSSION}

Out of the 300 participants total of $90(30 \%)$ individuals shown clinical features of anxiety, depression and mixed features of both anxiety and depression. Out of which $6(2 \%)$ participant had anxiety, 39 (13\%) had depression and 45 (15\%) had combined features of anxiety and depression. Bedaso et al., reported $17.4 \%$ of people had anxiety, and majority of them were female.(7) The result of both studies is almost similar, but data variability is may be due to uniqueness of this study, as this study also have participants with mixed features i.e. features of both anxiety and depression which is quite significant in number. Other reason of data variability could be due to different methodology of both studies. Choi et al., found that point prevalence of depression is $28 \%$, which is quite similar as this study describes. (8) As discussed, earlier data shows differences due to uniqueness of this study and due to different methodology used. In this study out of 300 HIV 
positive patients who had participated, 157 (52.3\%) was male and 143 (47.7) was female, out of 157 male participants, 02 $(.66 \%)$ male had anxiety, $20(6.66 \%)$ male had depression and $16(5.33 \%)$ had combined features of anxiety and depression, similarly out of 143 females participated $4(1.33 \%)$ female had anxiety, 19 (6.33\%) had depression, 29 (9.66\%) had combined features of both anxiety and depression. Hence, this study suggests that $52(37.14 \%)$ females had features of anxiety, depression and combined features of both. Similarly, 38 $(23.7 \%)$ of male had anxiety, depression and combined features of both. Overall, data analysis evaluated that female gender are more affected than male. The $\mathrm{p}$ value for anxiety is 0.34 and depression is 0.88 . The $P$ value $(0.002)$ for participant in combined group i.e. having both anxiety and depression is statistically significant. Adeoti et al., found that prevalence of depression and anxiety among PLHIV participant of 424 patients is $39.6 \%$ and $32.6 \%$ respectively as compared to control group which is $22 \%$ and $28.7 \%$, with female preponderance. The ratio of male to female is $1: 2.8$, and 1: 1.8 in case and control respectively, which signifies female preponderance. ${ }^{(9)}$ Hence both above mentioned shows female HIV positive participants was having more preponderance of anxiety and depression.

Pauline et al. Had conducted study on 400 HIV positive patients, out of which 152 were male and 248 were female. Of 152 males evaluated that $52(34.2 \%)$ having depression and $25(16 \%)$ having moderate to severe anxiety. Similarly, 141 (56.2\%) out of 252 having depression and 56 (26.2\%) female having anxiety, which also shows female preponderance of having depression and anxiety. Data variability in both studies may be due to different methodology used in both studies. (10) In this study out of 300 patients participated 102 (34\%) was in age group of 31 yrs. - 40 yrs., which total 38 (26.6\%) participant having anxiety 4 (1.3\%), depression 14 (4.6), 19 (6.3\%) having combined features of both which is much higher than other age group participants. The p-value for anxiety is 0.53 , depression is 0.16 and for combined is 0.29 . This result is statistically insignificant. Institutional based cross-section study in ALERT hospital in Addis Ababa, Ethiopia of 417 participants. In this study they found that middle age person $157(37.7 \%)$ was in the age group $31-40$ yrs. out of which $57(36.8 \%)$ had depression.(11) Both studies show that middle age 31-40 years participant are suffering from anxiety and depression among HIV positive patients as compared to other age group participant.

In this study most of the participant 194 (64.6\%) out of 300 is primary or secondary class educated out of which 55 (28.35\%), in which 1 had anxiety, 26 (13\%) had depression, $28(14.4 \%)$ had combined features of the anxiety and depression. The $\mathrm{p}$ value for anxiety is 0.6 , depression is 0.72 , and combined is 1.36, which is statistically insignificant. Bhatia and Munjal found that a degree of prevalence of depression is associated with less educated i.e. the participant that attended primary or secondary level of school.(12) Duko et al., reported that $165(45.5 \%)$ out of 363 was primary school educated maximally, in which 115 (69\%) having depression.(13) Both the study showed that lower level of education had high prevalence of depression. In this study majority of participants were housewives $89(30 \%)$ who was severely affected, in this total of $40(44.4 \%)$ housewives, $3(3.3 \%)$ had anxiety, 15 $(16.6 \%)$ had depression and $22(25 \%)$ had combined features of anxiety and depression. Other followed then are unemployed $42.85 \%$, private job $40.38 \%$, labor $26.6 \%$, Farmer $25.6 \%$. The $p$ value for anxiety is 0.82 , depression is 0.76 , and combined group is 0.7 , which is statistically insignificant. Bhatia and Munjal reported prevalence of depression is associated with occupation in army people $100 \%$, drivers $91.67 \%$, labor's $84.6 \%$ followed by commercial sex workers $84.5 \%$. Diversity in both results may be due to different method of data collection as well as different testing method. Preeti and Babu found that participant who are unemployed $36(34.6 \%)$ had the greatest number of depression and anxiety followed by un-skilled participants 33 (31.73\%), semiprofessional 12 (11.55\%), clerical people 7 (6.7\%), skilled 2 (1.91\%). Hence this study shows unemployed participant had major number of depression and anxiety. Diversity in results occupied by both studies is may be due to different methodology used for sampling and measures as well number of participant selected.(14) In this study out of 300 participant 255 candidates had more than $>200$ CD 4 count in which 71 (27.84\%) had 6 (2.35\%) anxiety, $33(12.9 \%)$ depression, 32 (12.6\%) combined features of both. 45 (42.2\%) participant had less than $<200 \mathrm{CD} 4$ count in which none of the patient had anxiety, 6 (13.3\%) had depression, and 13 (28.8\%) had combined features of both. This study demonstrates that participant who had less than 200 CD4 count had more anxiety, depression and combined features of both. The $p$ value for anxiety is 0.27 , depression is 0.27 and for combined is 0.11 , which is statistically insignificant.

This study also report depression of the patients was negatively associated with CD4 count which means high HDR score had lower level of CD4 count at the starting. Terloyeva, et al found that the prevalence of depression was more in participant having CD4 count less than 350 as compared with participant having CD4 counts more than 350 cells. In this study 102 participants are on ART having CD4 count less than 350 and 220 patients are having CD4 count more than 350 who are on ART.(15) $13.7 \%$ and $12.7 \%$ participant are having depression respectively. Both above mention studies clearly show that lower CD4 count are associated with depression. In these study participants was divided into ART duration up to 1 year, between 1-5 year, and more than 5 year. In each group there were 100 participants. Out of which ART taken for 1 years 41 participants shown, 1 anxiety, 20 had depression and 20 had combined features of both. ART taken between $1-5$ years duration, 4 participants had anxiety, 6 had depression, 9 had mixed features of both. Participant who had taken ART for more than 5 years 1 had anxiety, 13 had depression and 16 had mixed features of both. Hence this study demonstrates that participant who was on less than 1 year of ART duration had maximum number depression, anxiety and combined feature of both. The $p$ value for anxiety is 0.27 , depression is 0.51 , and for combined is 0.08 , which is statistically insignificant.

This study also report treatment year of the patients was positively associated with $\mathrm{CD} 4$ count at reassessment at the time of recruitment in the study $(-.085, \mathrm{p}<0.01)$ that means Duration of ART Regimen reported high level of CD4 count at present evaluation. Beyene et al found that $84.4 \%, 78.8 \%$, $86.6 \%$ are depression found in respective duration of ART taken. Both above mention study shows that people who are on ART less than 1 year had maximum number of patients of anxiety and depression. 


\section{CONCLUSIONS}

$30 \%$ individuals reported clinical features of anxiety, depression, and mixed features of both anxiety and depression. Female patients are more affected than male patients. Participants who were on less than 1 year of ART duration had maximum depression, anxiety and combined feature of both. Highly depressed patients reported lower level of CD4 count in the beginning. Treatment year of the patients was positively associated with higher CD4 count at present; duration of ART regimen was associated with high level of CD4 count at present. Therefore, early psychiatric intervention, psychological assessment, and treatment for depression or anxiety must be initiated to ensure better coping, treatment and long-term compliance for ART in people living with HIV.

Financial or Other Competing Interests: None.

\section{REFERENCES}

[1] Abraham OC, Susanne AP. API textbook of medicine. $10^{\text {th }}$ edn. Vol. 1. Mumbai: Dr. Yash Pal Munjal 2015:1374-5.

[2] World health organization. HIV/AIDS 2019. URL https://www.who.int/news-room/factsheets/detail/hiv-aids.

[3] National AIDS Control Organization. Living with HIV/AIDS 2019. URL http://naco.gov.in/living-hivaids.

[4] Edward H, Glenn JT. HIV and psychiatric illness. 2007. https://www.psychiatrictimes.com/schizophrenia/hiv -and-psychiatric-illness.

[5] Ciesla JA, Roberts JE. Meta-analysis of the relationship between HIV infection and risk for depressive disorder. Am J Psych 2001;158(5):725-30.

[6] Lundgren JD, Borges AH, Neaton JD. Serious non-aids condition in HIV: benefit of early art. Curr HIV/AIDS Rep 2018;15(2):162-71.
[7] Bedaso A, Belagavi D, Bekele G, et al. Factors associated with anxiety disorder among art clients attending antiretroviral therapy Clinic at Hawassa university referral hospital, Hawassa, SNNPR, Ethiopia. J Psychiatry 2016;20(1):1-5.

[8] Choi SK, Boyle E, Cairney J, et al. Prevalence, recurrence, and incidence of current depressive symptoms among people living with hiv in Ontario, Canada: results from the Ontario HIV Treatment Network Cohort Study. PLoS One 2016;11(11):e0165816.

[9] Adeoti AO, Dada MU, Fadare JO. Prevalence of depression and anxiety disorders in people living with HIV/AIDS in a Tertiary Hospital in South Western, Nigeria. Med Rep Case Studies 2018;3(1):1-6.

[10] Ng'ang'a PW, Mathai M, Obondo A, et al. Undetected psychiatric morbidity among HIV/AIDs patients attending Comprehensive Care Clinic (CCC) in Nairobi Kenya: towards an integrated mental health care. Ann Gen Psychiatry 2018;17:11.

[11] Tesfaw G, Ayano G, Awoke T, et al. Prevalence and correlates of depression and anxiety among patients with HIV on-follow up at Alert Hospital, Addis Ababa, Ethiopia. BMC Psychiatry 2016;16(1):368.

[12] Bhatia MS, Munjal S. Prevalence of depression in people living with HIV/AIDS undergoing art and factors associated with it. J Clin Diagn Res 2014;8(10):WC01-4.

[13] Duko B, Toma A, Asnake S, et al. Depression, anxiety and their correlates among patients with HIV in South Ethiopia: an institution based cross-sectional study. Front Psychiatry 2019;10:290.

[14] Rai P, Verma BM. A study on depression in people living with HIV/AIDS in south-west part of Uttar Pradesh, India. South East Asia J Public Health 2015;5(1):12-17.

[15] Gebrezgiabher BB, Abraha TH, Hailu E, et al. Depression among adult HIV/AIDS patients attending ART clinics at Aksum Town, Aksum, Ethiopia: a cross-sectional study. Depress Res Treat 2019:2019:1-8. 